\title{
Preference of Food-items and Physical Activity of Peri-urban Children in Bhaktapur
}

\begin{abstract}
Abhinav Vaidya, ${ }^{1}$ Natalia Oli, ${ }^{1,2}$ Alexandra Krettek, ${ }^{2,3,4}$ Gabriele Eiben ${ }^{3,5}$
${ }^{1}$ Department of Community Medicine, Kathmandu Medical College, Kathmandu, ${ }^{2}$ Department of Internal Medicine and Clinical Nutrition, Institute of Medicine, Sahlgrenska Academy at University of Gothenburg, Gothenburg, Sweden, 3Department of Biomedicine and Public Health, School of Health and Education,University of Skövde, Skövde, Sweden, ${ }^{4}$ Department of Community Medicine, Faculty of Health Sciences, UiT The Arctic University of Norway, Tromso, Norway, ${ }^{5}$ Department of Public Health and Community Medicine, University of Gothenburg, Gothenburg, Sweden.
\end{abstract}

\section{ABSTRACT}

Background: Though cardiovascular diseases are mostly seen in adulthood, foundation of diet and physical activity is largely formed during childhood. The study aimed to explore children's preference for diet and physical activity in a peri-urban area of Nepal because this is an important dimension to explore in the life-course approach to combat non-communicable diseases.

Methods: We conducted a cross-sectional study to enquire young peri-urban children of Duwakot and Jhaukhel villages of Bhaktapur district, Nepal on their preferences for diet and physical activity. All eligible households with children in the age range 5-10 years as enlisted from the Jhaukhel-Duwakot Health Demographic Surveillance Site database were selected for the study. Twelve enumerators visited the selected households and facilitated the eligible children to fill in the questionnaire. We used a child-friendly photo-assisted questionnaire with face-scales that easily enabled the children to select a particular preference for each of the food item and physical activity. During analysis, food items were categorized into 'green', 'yellow' and 'red' on the basis of their nutritive values. Physical activity was categorized based on severity of the activity.

Results: Four hundred and thirty seven children filled up the questionnaires. Overall, median preference scores for 'red' food were higher than for healthier 'green' food (4.16 vs. 4.03), particularly, if mothers were self-employed. Likewise, the children preferred low over moderate-to-severe physical activity (4.16 vs. 3.50), and preference was affected by parents' occupation and income.

Conclusions: The study objectively revealed that most of the children preferred unhealthier food-items and low physical activities. It shall be useful to consider these findings while planning health promotional activities targeted at them.

Keywords: Children; diet; preferences; Nepal; physical activity.

\section{INTRODUCTION}

Unhealthy diet and physical inactivity contribute to the non-communicable diseases (NCDs), ${ }^{1,2}$ particularly in low-and middle-income countries. ${ }^{3}$ Though adults are mostly affected, changes begin early in life. ${ }^{4}$ Hence, applying a life-course approach is a critical strategy ${ }^{5}$ as adult health behaviour is formed during young age, ${ }^{6}$ and can potentially be modified. ${ }^{7}$ NCD risk factors are rising, ${ }^{8}$ particularly in Nepal's urbanising settings. ${ }^{9}$ Nepalese adolescents have high risk factors, ${ }^{10}$ coupled with inadequate knowledge. ${ }^{11}$
Data from the peri-urban Jhaukhel-Duwakot Health Demographic Surveillance Site (JD-HDSS) also demonstrates that cardiovascular risk factors are common, ${ }^{12}$ with limited awareness even among the diseased ${ }^{13}$ and also among young mothers. ${ }^{14}$ Indeed, many factors determine children's eating habits and physical activity, ${ }^{15,16}$ of which their preference for a particular food and activity can be a strong determinant. ${ }^{17}$ This aspect has been studied mainly in high-income countries. ${ }^{18-20}$ We undertook this study in this peri-urban setting of Nepal to explore children's dietary and physical activity preferences. 


\section{METHODS}

This cross-sectional study was conducted in JD-HDSS, a peri-urban area in the Kathmandu valley about 15 kilometres from the capital Kathmandu and comprising the former villages Jhaukhel and Duwakot. From the JD-HDSS database, a sampling list of households with children aged 5-10 years was prepared.The reason for choosing five years as the lower cut-off was that it would have been very difficult for children younger than five years to fill in the questionnaires on their own. Likewise, we put the upper cut off at ten years as the mothers in our focus groups had expressed that it was very difficult to influence dietary and physical activity behaviour of those above 10 years or so. ${ }^{14}$ We intended to include all these households in our sample.

Twelve enumerators received 5-days training on data collection. They did door-to-door visits to all the listed households between August-November 2014. Children aged 5-10 years in the households filled in the questionnaire in their presence but without interference of other family members. Enumerators randomly picked one child if there were more than one eligible child in the household. Children who were not keen to participate were excluded from data collection process. The enumerator facilitated the process if the child had any query or needed help understanding the questions. Enumerators were continuously supervised in the field by three public health graduates, and intermittently by two authors (AV, NO).

We developed our questionnaire containing 64 food items along the lines of the child food preference questionnaires used earlier. ${ }^{18,19,21}$ First, we prepared a list of most commonly available food-items in the local context, and categorized them 'intogreen', 'yellow' and 'red'. Because Nepal does not have a dietary guideline, we did the classification into these three categories following the methods adapted in similar studies ${ }^{22,23}$ in other settings, supplemented by consultation with national and international experts working in the field of childhood nutrition.

'Green' foods were defined as food items that contain nutrients that are good for health and growth of children, and they are usually not harmful even when consumed in large amounts. We defined 'red' foods as those that contain high amounts of unhealthy ingredients including trans-fat, sugar, etc. 'Yellow' food items were those that do not contain adequate nutrients, or which are likely to replace staple and healthy food if taken regularly or in large quantities. Altogether 28 'green', 25 'red' and 11 'yellow' food items were listed (Table 1). All food items were illustrated with photos in the questionnaire.

Table 1. Categorisation of the food-items into 'Green', 'Yellow' and 'Red'.

'Green' 'Yellow' 'Red'

1. White

1. Cauliflower bread 1. Sel-rotim

2. Cabbage 2. Tea 2. Doughnut

3. Green vegetables 3. Pickle 3. Tomato Sauce ${ }^{n}$

4. Tetra-pack juice (Real/

4. Roasted corn 4. Ghees Frooti) $^{\circ}$

5. Green Salad

5. Butter ${ }^{\mathrm{g}}$ 5. Fried potatoes

6. Cooked

6. Orange Meat $^{\text {h }}$

6. Samosap

7. Pulse

7. Momo ${ }^{i}$ 7. Sausage

8. Horlicks/

8. Beaten rice Viva $^{j}$

8. Cream roll

9. Bhujia/ Dal-

9. Whole milk 9. Biscuits ${ }^{k} \quad$ moth $^{q}$

10. Pudding ${ }^{a}$ 10. Puril 10. Cheese Balls

11. Corn

11. Kwanati flakes 11. Chatpate

12. Guava 12. Chips/Kurkure

13. Grams ${ }^{c}$ 13. Titaura ${ }^{t}$

14. Grapes 14. Pani-puriu

15. Tofu

15. Coke/ Fanta/ Sprite

16. Gundruk ${ }^{d}$

16. Chocos/Crispies

17. Chocolate/

17. Peanuts candy

18. Mango

18. Mithaiv

19. Banana

19. Cake

20. Mashyaura

20. Halwaw

21. Cashew

21. Instant nut Noodles $^{x}$

22. Curd

22. Ice cream

23. Fresh fruit Juice

23. Chow-mein

24. Water

24. Jam

25. Rice

25. Sugar

27. Fish

28. Egg 
${ }^{a}$ pudding in Nepal is generally cooked with rice grains, milk, and nuts and raisins are added as toppings, and generally without added sugar

\section{${ }^{b}$ soup made of an assortment of nine different beans}

' $a$ category of pulses and hence rich in protein; common in the Indian sub-continent.e.g. red gram, horse gram, green gram, etc.

${ }^{d}$ fermented dried green leafy vegetables cooked as curry

eNepali curry with soybean dumplings

${ }^{f}$ flat bread, made from stone-ground whole flour

${ }^{s}$ both ghee and butter are $100 \%$ fat. While slight amount is beneficial to the children as they can provide the RDA of fat in children ('healthy') but their consumption in many items (especially ghee in Nepalese context) can predispose children to obesity and atherosclerotic changes.

${ }^{h}$ meat in Nepal is usually cooked with lots of oil and spices, and pure lean meat is rarely consumed

'steamed dumpling often filled with minced chicken skin, buffalo offal and other unhealthy meat parts

${ }^{b}$ because of their fierce marketing, parents often take these supplementary food as more nutritious and hence tend to replace natural food with these. Often, they are also taken as status symbols and parents feel proud if they are able to feed their children with horlicks/viva

kcommonly available (and affordable) biscuits are prepared mainly from wheat flour and eligible oil, with added ingredients such as artificial flavours and emulsifiers, etc. The food itself is quite 'benign' but in Nepal, most people have tendency to have biscuits as the main food in breakfasts and afternoon snacks. In other words, they are over-consumed.

I a small, round piece of bread made of unleavened wheat flour, deep-fried and served with meat or vegetables

${ }^{m}$ a Nepali traditional home-made, sweet, ring-shaped rice bread/doughnut, deep fried in boiling oil or ghee

"commercial 'tomato sauce' which are very widely used are basically some plant saps that have been artificially red-coloured

othey do not actually contain fruit juice but artificially flavoured drinks. They are very popular, and people perceive them to be better than soft drinks because they contain 'fruit juice'

${ }^{p}$ a triangular savoury pastry deep fried in ghee or oil, containing spiced vegetables
${ }^{a}$ a traditional crispy, spicy, and salty dry snack made from deep fried lentils, nuts, spices, and oil

rMix of the textures (roasted rice, grams, peanut) and served fresh(tomato, cucumber, onion, ginger, fresh coriander) and the flavours (yellow lime, tamarind sauce, mustard oil, spices) all mixed served in a paper cone, usually sold by street vendors. The base is deep fried and the sauce contains high amount of salt.

spackaged puffs in corn with salt and spices

${ }^{t}$ sweet, sour, salty or hot or mixture of all those made from fruits like Nepali Hog Plum; consumed a lot by young children, often instead of real snacks; contains a lot of salt.

"a street snack that consists of a round, hollow deepfried wheat bread filled with a mixture of flavoured water, tamarind chutney, potato, etc

'Indian sweets and include sugar, and a vast array of ingredients such as different flours, milk, milk solids, fermented foods, root vegetables, raw and roasted seeds, seasonal fruits, fruit pastes and dry fruits

wdense, sweet confections made with wheat flour and sugar

xInstant noodles have literally invaded the eating habit of the Nepalese, especially children. They are seen as the most convenient snack and often even the main meals (eat in right out of the packet, or boil it in water for two minutes). They do not provide much nutrition as they are made of refined flour and flavours. In addition, they contain high levels of salt and hydrogenated fats and often contain the dangerous mono-sodium glutamate.

For each food item, there were six response options: 1-5 for increasing order of preference and accompanied by a five point 'face-scale' that immensely increased userfriendliness of the questionnaire, and a 'never tried/ don't know' option which was scored zero. Children were asked to circle the number in the appropriate box. The 64 food items did not appear in any particular order in the questionnaire.

Physical activity was categorized into 'moderate to vigorous physical activity (MVPA)' and 'low physical activity (LPA) ${ }^{24}$ by first listing common activities related to the children's context in Nepal. Activities termed 'MVPA' indicated those that require active movement of the gross muscles of the body and included the following six activities: playing outdoors, swimming, helping family in the garden/field, playing football, cycling and kite-flying. 'LPA' activities included six activities that are sedentary or need minimal muscle movements: computer-related activities, playing with dolls/toys, 
watching TV/cartoon, studying, playing carom (a "strike and pocket" table game of Eastern origin similar to billiards and table shuffleboard) and playing mobile games. Like for food-items, a five-point preference score with face-scale and a 'never tried/don't know' option was used for physical activity.

The enumerators also collected data on the sociodemographic variables of the children from the adult family members of the family: sex, age, ethnicity, mother's education, parents' occupation, and monthly household income.

Data was entered in Epidata 3.1 and analyzed with SPSS version 20.0. We aggregated scores for the 28 'green', 11 'yellow' and 25 'red' food itemsinto 'green' food score, 'yellow' food score and 'red'food score, respectively. Similarly,we also aggregated scores from the six MVPA and six LPA into 'MVPA score' and 'LPA score', respectively. We calculated medians and interquartile ranges for preference scores for each aggregated group of food items and physical activities, and compared them across socio-demographic variables. We used Wilcoxon signed rank test to compare the median preference scores in each category of the socio-demographic variables - for 'green', 'yellow' and 'red' food items, and for comparing preference scores for MVPA and LPA. For comparing median preference scores across categories of socio-demographic variables, we used independent samples Kruskal Wallis test. P-value less than 0.05 was considered statistically significant. We used SPSS version 20 for data analysis.

We pre-tested the questionnaire in 20 children aged 5-10 years in Kathmandu, and we found that even smaller children did not have any problem in comprehending and answering the questions, and they rather enjoyed filling them in. The study received ethical approval from the Nepal Health Research Council. Verbal consent for children's participation was given by family members present in the households at the time of data collection and by the children themselves.

\section{RESULTS}

Table 2. Median food preference scores of the children according to their background variables.

Of the total 470 children aged 5-10 years in the study area, 437 children participated in the study (response rate: $93 \%)$. Boys and girls were in almost equal proportion (49.7\% vs. $50.3 \%$ ). Children aged $5-7$ years constituted $75.1 \%$ of the study population while the remaining $24.9 \%$ were aged 8-10 years. The demographic details of the children are given in Table 2.

Regarding food preferences, children's overall median preference scores with their interquartile ranges for 'green' food, 'yellow' food and 'red' food were 4.03 (0.66), $3.81(0.90)$ and $4.16(0.92)$, respectively. Most preferred 'red' food items, for example, ice-cream, chocolate, carbonated drinks, noodles, etc. Most 'green' foods, such as fruits and vegetables, ranked lower than 'red' foods in preference.

Table 2 shows the scores among the various sociodemographic subsets of children. The table makes a twoway comparison of the preference scores: a horizontal comparison of scores for 'green', 'yellow' and 'red' food items at each level of category of variables (e.g. whether boys have higher preference for 'green' food, 'yellow' food or 'red' food compared to girls); and also a vertical comparison among each category of the sociodemographic variables for each of the three food groups (e.g. whether boys or girls have higher preference for 'green' food).

Compared to the 'green' and 'red' food items, the 'yellow' food items scored lowest across most of the variables $(p<0.001)$. Importantly, preference for 'red' food was higher than for 'green' food among most of the children- and significantly so, if they were of Newar ethnicity $(p=0.009)$, or if the mother's occupation was self-employment or private job $(\mathrm{P}=0.001)$. In terms of socio-demographic variables, there were no statistically significant differences for preferences in the three categories of food-items (Table 2).

Regarding physical activity preference, the children preferred LPA over MVPA with the median (inter-quartile range, IQR) preference scores being 4.16 (IQR 1.50) and 3.50 (IQR 1.66), respectively. Studying, watching TV/

\begin{tabular}{|c|c|c|c|c|c|c|c|c|}
\hline & \multirow[t]{2}{*}{ Number } & \multirow[t]{2}{*}{ Percent } & \multicolumn{3}{|c|}{ Food preference score [median(IQR)] } & \multirow[b]{2}{*}{$\begin{array}{l}\text { 'Green } \\
\text { vs. 'Red' }\end{array}$} & \multirow[b]{2}{*}{$\begin{array}{l}\text { ‘Green' vs. } \\
\text { 'Yellow' }\end{array}$} & \multirow{2}{*}{$\begin{array}{l}\text { p-value* } \\
\text { 'Yellow' } \\
\text { vs. 'Red' }\end{array}$} \\
\hline & & & ‘Green' food & 'Yellow' food & 'Red' food & & & \\
\hline \multicolumn{9}{|l|}{ Sex } \\
\hline Male & 217 & 49.7 & $4.00(0.65)$ & $3.73(0.91)$ & $4.12(0.92)$ & 0.438 & $<0.001$ & $<0.001$ \\
\hline Female & 220 & 50.3 & $4.07(0.68)$ & $3.90(0.91)$ & $4.20(0.92)$ & 0.353 & 0.001 & $<0.001$ \\
\hline p-value\# & & & 0.40 & 0.103 & 0.187 & & & \\
\hline
\end{tabular}




\begin{tabular}{|c|c|c|c|c|c|c|c|c|}
\hline \multicolumn{9}{|l|}{ Age (years) } \\
\hline $5-7$ & 328 & 75.1 & $4.03(0.68)$ & $3.81(0.91)$ & $4.16(0.92)$ & 0.403 & $<0.001$ & $<0.001$ \\
\hline $8-10$ & 109 & 24.9 & $4.02(0.55)$ & $3.86(0.91)$ & $4.12(0.92)$ & 0.249 & $<0.001$ & $<0.001$ \\
\hline \multicolumn{3}{|l|}{$\mathrm{p}$-value } & 0.997 & 0.316 & 0.982 & & & \\
\hline \multicolumn{9}{|l|}{ Ethnicity } \\
\hline Newar & 125 & 28.6 & $3.96(0.75)$ & $3.82(0.82)$ & $4.16(0.86)$ & 0.009 & 0.006 & $<0.001$ \\
\hline Hill Brahmin & 85 & 19.5 & $4.21(0.56)$ & $3.82(1.09)$ & $4.08(1.08)$ & 0.086 & $<0.001$ & $<0.001$ \\
\hline Chhetri & 147 & 33.6 & $4.03(0.54)$ & $3.82(0.91)$ & $4.08(1.00)$ & 0.680 & $<0.001$ & $<0.001$ \\
\hline Other & 80 & 18.3 & $4.00(0.34)$ & $3.90(0.44)$ & $4.20(0.96)$ & 0.328 & 0.004 & 0.002 \\
\hline \multicolumn{2}{|l|}{$\mathrm{p}$-value } & & 0.219 & 0.830 & 0.562 & & & \\
\hline \multicolumn{9}{|c|}{ Mother's education } \\
\hline$\leq$ primary & 255 & 58.4 & $4.00(0.64)$ & $3.82(0.91)$ & $4.12(0.93)$ & 0.337 & $<0.001$ & $<0.001$ \\
\hline$\geq$ secondary & 182 & 41.6 & $4.07(0.68)$ & $3.82(1.00)$ & $4.16(0.93)$ & 0.395 & $<0.001$ & $<0.001$ \\
\hline \multicolumn{2}{|l|}{$\mathrm{p}$-value ${ }^{\#}$} & & 0.285 & 0.890 & 0.396 & & & \\
\hline \multicolumn{9}{|c|}{ Mother's occupation } \\
\hline $\begin{array}{l}\text { Agriculture and } \\
\text { labour }\end{array}$ & 50 & 11.4 & $3.87(1.06)$ & $3.86(0.82)$ & $4.24(0.61)$ & 0.083 & 0.031 & $<0.001$ \\
\hline $\begin{array}{l}\text { Self-employed/ } \\
\text { private job }\end{array}$ & 50 & 11.4 & $4.03(0.54)$ & $4.13(0.77)$ & $4.26(0.92)$ & 0.001 & 0.317 & $<0.001$ \\
\hline Housewife & 322 & 73.7 & $4.03(0.61)$ & $3.82(1.00)$ & $4.12(0.96)$ & 0.661 & $<0.001$ & $<0.001$ \\
\hline Other & 15 & 3.4 & $4.16(0.95)$ & $3.72(0.68)$ & $4.12(1.19)$ & 0.650 & 0.088 & 0.061 \\
\hline \multicolumn{2}{|l|}{$\mathrm{p}$-value } & & 0.063 & 0.289 & 0.164 & & & \\
\hline \multicolumn{9}{|c|}{ Father's occupation } \\
\hline $\begin{array}{l}\text { Agriculture and } \\
\text { labour }\end{array}$ & 95 & 21.7 & $4.00(0.54)$ & $3.65(0.53)$ & $4.10(0.98)$ & 0.151 & 0.002 & $<0.001$ \\
\hline $\begin{array}{l}\text { Government } \\
\text { service }\end{array}$ & 101 & 23.1 & $4.00(0.68)$ & $3.81(0.91)$ & $4.16(0.92)$ & 0.755 & $<0.001$ & $<0.001$ \\
\hline $\begin{array}{l}\text { Self-employed/ } \\
\text { private job }\end{array}$ & 160 & 36.6 & $4.00(0.77)$ & 3.81 (1.79) & $4.18(1.43)$ & 0.300 & $<0.001$ & $<0.001$ \\
\hline $\begin{array}{l}\text { Foreign } \\
\text { employment }\end{array}$ & 52 & 11.9 & $4.03(0.57)$ & $4.09(0.91)$ & $4.20(0.96)$ & 0.402 & 0.001 & 0.060 \\
\hline Other & 29 & 6.6 & $4.28(0.88)$ & $3.68(1.50)$ & $3.92(1.16)$ & 0.085 & 0.377 & 0.090 \\
\hline \multicolumn{2}{|l|}{$\mathrm{p}$-value ${ }^{\#}$} & & 0.389 & 0.374 & 0.722 & & & \\
\hline \multicolumn{9}{|c|}{ Monthly household income (NRs) } \\
\hline$<15000$ & 172 & 39.4 & $4.03(0.79)$ & $3.81(1.00)$ & $4.12(0.92)$ & 0.441 & $<0.001$ & $<0.001$ \\
\hline$\geq 15000$ & 265 & 60.6 & $4.03(0.61)$ & $3.82(0.91)$ & $4.20(0.92)$ & 0.170 & $<0.001$ & $<0.001$ \\
\hline \multicolumn{3}{|l|}{$\mathrm{p}$-value $\mathrm{e}^{\#}$} & 0.974 & 0.940 & 0.322 & & & \\
\hline $\begin{array}{l}{ }^{*} \text { Wilcoxon signea } \\
\text { Independent sam }\end{array}$ & test & 'red' & $\begin{array}{l}\text { 'green' fooc } \\
\text { st (for catego }\end{array}$ & 'green' vs. 'y & $\begin{array}{l}\text { ellow' food a } \\
\text { variable); } 1 Q\end{array}$ & 'yellow & 'red' fo & \# \\
\hline
\end{tabular}

\begin{tabular}{|c|c|c|c|c|c|}
\hline & \multirow{2}{*}{ Number } & \multirow{2}{*}{ Percent } & \multicolumn{2}{|c|}{$\begin{array}{l}\text { Leisure time activity preference score } \\
\text { [median (IQR)] }\end{array}$} & \multirow[t]{2}{*}{$\mathrm{p}$-value * } \\
\hline & & & $\begin{array}{l}\text { Moderate-to-vigorous } \\
\text { physical activity }\end{array}$ & $\begin{array}{l}\text { Low physical } \\
\text { activity }\end{array}$ & \\
\hline \multicolumn{6}{|l|}{ Sex } \\
\hline Male & 217 & 49.7 & $3.66(1.33)$ & $4.33(1.33)$ & $<0.001$ \\
\hline Female & 220 & 50.3 & $3.17(1.83)$ & $4.00(1.33)$ & $<0.001$ \\
\hline
\end{tabular}




\begin{tabular}{|c|c|c|c|c|c|}
\hline $\mathrm{p}$-value $\mathrm{e}^{\#}$ & & & $<0.001$ & 0.164 & \\
\hline \multicolumn{6}{|l|}{ Age (years) } \\
\hline $5-7$ & 328 & 75.1 & $3.33(1.83)$ & $4.16(1.50)$ & $<0.001$ \\
\hline 8-10 & 109 & 24.9 & $3.66(1.42)$ & $4.16(1.58)$ & $<0.001$ \\
\hline $\mathrm{p}$-value ${ }^{\#}$ & & & 0.548 & 0.467 & \\
\hline \multicolumn{6}{|l|}{ Ethnicity } \\
\hline Newar & 125 & 28.6 & $4.00(1.75)$ & $3.33(1.79)$ & $<0.001$ \\
\hline Hill Brahmin & 85 & 19.5 & $3.33(1.33)$ & $3.83(1.50)$ & $<0.001$ \\
\hline Chhetri & 147 & 33.6 & $3.66(1.00)$ & $4.50(1.29)$ & $<0.001$ \\
\hline Other & 80 & 18.3 & $3.33(1.33)$ & $4.17(1.33)$ & $<0.001$ \\
\hline $\mathrm{p}$-value ${ }^{\#}$ & & & 0.142 & 0.081 & \\
\hline \multicolumn{6}{|l|}{ Mother's education } \\
\hline$\leq$ primary & 255 & 58.4 & $3.50(1.71)$ & $4.16(1.50)$ & $<0.001$ \\
\hline$\geq$ secondary & 182 & 41.6 & $3.50(1.50)$ & $4.33(1.33)$ & $<0.001$ \\
\hline p-value & & & 0.433 & 0.152 & \\
\hline \multicolumn{6}{|l|}{ Mother's occupation } \\
\hline Agriculture and labour & 50 & 11.4 & $3.33(1.33)$ & $4.00(1.17)$ & 0.001 \\
\hline Self-employed/private job & 50 & 11.4 & $3.50(1.50)$ & $4.16(1.33)$ & $<0.001$ \\
\hline Housewife & 322 & 73.7 & $3.50(1.67)$ & $4.16(1.50)$ & $<0.001$ \\
\hline Other & 15 & 3.4 & $3.50(1.67)$ & $4.50(1.33)$ & 0.013 \\
\hline p-value ${ }^{\#}$ & & & 0.768 & 0.038 & \\
\hline \multicolumn{6}{|l|}{ Father's occupation } \\
\hline Agriculture and labour & 95 & 21.7 & $3.33(2.17)$ & $3.83(1.79)$ & 0.001 \\
\hline Government service & 101 & 23.1 & $3.50(1.83)$ & $4.33(1.33)$ & $<0.001$ \\
\hline Self-employed/private job & 160 & 36.6 & $3.55(1.50)$ & $4.33(1.42)$ & $<0.001$ \\
\hline Foreign employment & 52 & 11.9 & $3.50(1.29)$ & $4.16(1.17)$ & $<0.001$ \\
\hline Other & 29 & 6.6 & $3.66(1.88)$ & $3.75(2.00)$ & 0.312 \\
\hline$p$-value ${ }^{\#}$ & & & 0.339 & 0.003 & \\
\hline \multicolumn{6}{|l|}{$\begin{array}{l}\text { Monthly household income } \\
\text { (NRs) }\end{array}$} \\
\hline$<15000$ & 172 & 39.4 & $3.50(1.87)$ & $4.00(1.75)$ & $<0.001$ \\
\hline$\geq 15000$ & 265 & 60.6 & $3.33(1.67)$ & $4.33(1.33)$ & $<0.001$ \\
\hline p-value ${ }^{\#}$ & & & 0.822 & 0.036 & \\
\hline
\end{tabular}

*Wilcoxon signed rank test (for active vs. inactive) \#Independent samples Kruskal Wallis test (for categories across the variable)

cartoons and playing with toys and dolls were the most preferred activities. Children gave less preference to outdoor activities such as playing football, swimming and helping family members in the garden or field.

Physical activity preference scores for MVPA and LPA in the different categories of the background variables are shown in Table 3. Similar to Table 2, Table 3 demonstrates two-way comparisons, horizontally and vertically. We found that most children, irrespective of their socio-demographic background, preferred LPA over MVPA $(p \leq 0.05)$ (Table 3$)$. Further, boys preferred MVPA more than girls ( $p<0.001)$. Children's preference, for both MVPA and LPA, did not significantly differ by their age, ethnicity, mother's education or occupation. The preference for LPA, however, was affected by occupation of their father $(p=0.003)$ and mother $(p=0.038)$ and by monthly household income $(p=0.036)$.

\section{DISCUSSION}

In the presence of high prevalence of inadequate physical activity and unhealthy diet intake in Nepalese children, ${ }^{10}$ assessment of children's preferences is 
indeed an important determinant of their behaviour. As children's diet and physical activity preferences have not been previously studied in Nepal, we conducted this study to bridge this knowledge gap. Our study investigated dietary and physical activity preference scores of 437 children residing in a peri-urban area of Nepal through a self-administered questionnaire. On the whole, the children preferred unhealthy over healthy food items and low physical activities over moderate-tovigorous physical activities.

Preference-based questionnaires like the one that we used in the study have come into use relatively late and are used less commonly ${ }^{22}$ compared to questionnaires that explore children's eating behaviour, ${ }^{25,26}$ or activity practices. ${ }^{27}$ Nonetheless, preference-focused studies show that these correlate positively with health behaviour of children, including attitude towards physical education. ${ }^{20}$ We therefore developed a child preference questionnaire to determine the children's preferences modelled on internationally validated tools ${ }^{18,19}$ and adapted them to the local context.

Asking parents about their children's preferences can be misleading and incorrect. While parents' own food preferences correlate well with the perceived preferences of their children, only half of the children's actual preferences match correctly with what their parents thought they preferred. ${ }^{22}$ Similarly, while parents' preferences on physical activity also positively correlate with their children's preferences, ${ }^{17}$ parents' perception regarding children's physical activity preferences do not align with children's own preferences. ${ }^{28}$

Of the various socio-demographic correlates we explored, higher family income is one factor in our study that was associated with higher preference scores for both unhealthy diet and inactive physical activities - a finding which is shared also by others. ${ }^{22}$ However, unlike other studies, ${ }^{18}$ age of the children in our study did not influence dietary or physical activity preferences.

A major strength of the study is the fact that it has objectively explored, for the first time in Nepal, children's preferences on diet and physical activity. Indeed, this knowledge about children's preferences can have great public health impact as it provides useful insight for planning healthy behavioural interventions in children. None the less, our study has certain limitations too. As a Nepali guideline on healthy food is lacking, we developed our own categorisation of green, yellow and red food, which may seem subjective. Small children responding to thequestions can also lead to misreporting bias, which we tried to minimize by making the questionnaire as simple as possible that relied more on drawings and pictures than the texts. We unintentionally excluded question on education of the father which can also influence children's preferences. Furthermore, besides the socio-demographic factors, dietary preferences are also affected by various environmental influences and genetic predispositions. ${ }^{29}$ Similarly, physical activity preferences are also influenced by various sociocultural ${ }^{27}$ and parental facilitators and barriers. ${ }^{30}$ However, it was beyond the scope of our study to explore these factors.

\section{CONCLUSIONS}

Children from peri-urban Nepal showed greater preference for unhealthy diet and low physical activity. Parental income and mothers' education negatively influenced preferences of these children. Indeed, dietary and physical activity preferences of children are important to consider while developing heart-health promotional interventions, not only for CVDs but also for other non-communicable diseases that share these two behavioural risk factors.

\section{REFERENCES}

1. Kohl HW, Craig CL, Lambert EV, Inoue S, Alkandari JR, Leetongin G, et al. The pandemic of physical inactivity: global action for public health. Lancet. 2012;380(9838):294-305 [S cience Direct]

2. Moodie R, Stuckler D, Monteiro C, Sheron N, Neal B, Thamarangsi T, et al. Profits and pandemics: prevention of harmful effects of tobacco, alcohol, and ultra-processed food and drink industries. Lancet. 2013;381(9867):67079. [ $\underline{\text { Science Direct }]}$

3. Popkin BM. The shift in stages of the nutrition transition in the developing world differs from past experiences! Public Health Nutr. 2002;5(1A):205-14. Link

4. Weintraub WS, Daniels SR, Burke LE, Franklin BA, Goff DC Jr, Hayman LL, et al. Value of primordial and primary prevention for cardiovascular disease a policy statement from the American Heart Association. Circulation. 2011;124(8):967-90. Link

5. Godfrey KM, Gluckman PD, Hanson MA. Developmental origins of metabolic disease: life course and intergenerational perspectives. Trends Endocrinol Metab. 2010;21(4):199-205.Link

6. Kelder SH, Perry CL, Klepp KI,Lytle LL. Longitudinal tracking of adolescent smoking, physical activity, and food choice behaviors. Am J Public Health. 1994;84(7):112126. Link 
7. Williams CL, Hayman LL, Daniels SR, Robinson TN, Steinberger J, Paridon S, et al. Cardiovascular Health in Childhood A Statement for Health Professionals From the Committee on Atherosclerosis, Hypertension, and Obesity in the Young (AHOY) of the Council on Cardiovascular Disease in the Young, American Heart Association. Circulation. 2002;106(1):143-60. Link

8. Aryal KK, Mehata S, Neupane S, Vaidya A, Dhimal M, Dhakal P, et al. The Burden and Determinants of Non Communicable Diseases Risk Factors in Nepal: Findings from a Nationwide STEPS Survey. PloS One. 2015;10(8):e0134834. Link

9. Oli N, Vaidya A, Thapa G. Behavioural risk factors of noncommunicable diseases among Nepalese Urban poor: A descriptive study from a Slum Area of Kathmandu. Epidemiology Research International. 2013;2013. Available at: http: / /dx.doi.org/10.1155/2013/329156 Link

10. Pyakurel M.Ghimire A, Pokharel P. Cardiovascular Risk Factors among adolescents of Nepalgunj Municipality in Nepal.Geneva Health Forum Archive; 2013. Available from:http://ghf.g2hp.net/2013/09/14/cardiovascularrisk-factors-among-adolescents-of-nepalgunj-municipality-in-nepal. (Cited 23 March 2016).

11. Yadav KD, Wagle R. Knowledge and attitude regarding major risk factors of cardiovascular diseases among 15-19 year old students of Kathmandu District. Health Prospect. 2013;11:7-10. Link

12. Vaidya A, Aryal UR, Krettek A. Cardiovascular health knowledge, attitude and practice/behaviour in an urbanising community of Nepal: a population-based cross-sectional study from Jhaukhel-Duwakot Health Demographic Surveillance Site. BMJ Open. 2013;3(10):e002976. Link

13. Oli N, Vaidya A, Subedi M, Krettek A. Experiences and perceptions about cause and prevention of cardiovascular disease among people with cardiometabolic conditions: findings of in-depth interviews from a peri-urban Nepalese community. Glob Health Action. 2014; 7: $10.3402 /$ gha.v7.24023. Link

14. Oli N, Vaidya A, Subedi M, Eiben G, Krettek A. Diet and physical activity for children's health: a qualitative study of Nepalese mothers' perceptions. BMJ Open. 2015;5(9):e008197. Link

15. Hinkley T, Crawford D, Salmon J, Okely AD, Hesketh K. Preschool children and physical activity: a review of correlates. Am J Prev Med. 2008;34(5):435-41. e7. Link

16. Taylor JP, Evers S, McKenna M. Determinants of healthy eating in children and youth. Can J Public Health. 2005:S20S26. Link
17. Janie M. Leary DA, Sherry K. Gaines, Judith L. Wold MM. Measurement of activity preferences of preschoolers and caregivers. Education and Health. 2008;26(4):3. Link

18. Cooke LJ, Wardle J. Age and gender differences in children's food preferences. Br J Nutr. 2005;93(05):741-46. $\underline{\text { Link }}$

19. Sharma S, Roberts LS, Hudes ML, Fleming SE. Food Preferences Assessment: Development of a Questionnaire and Evaluation of Reliability in African American and Latino Children from Low Socio Economic Area. J Nutr Food Sci.2012; S8:001. Link

20. Zeng HZ, Hipscher M, Leung RW. Attitudes of high school students toward physical education and their sport activity preferences. Journal of Social Sciences. 2011;7(4):529. $\underline{\text { Link }}$

21. Deglaire A, Méjean C, Castetbon K, Kesse-Guyot E, Urbano C, Hercberg S, et al. Development of a questionnaire to assay recalled liking for salt, sweet and fat. Food Qual Pref. 2012;23(2):110-24. Link

22. De Lira-García C, Bacardí-Gascón M, Jiménez-Cruz A. Preferences of healthy and unhealthy foods among 3 to 4 year old children in Mexico. Asia Pac J Clin Nutr. 2012;21(1):57. Link

23. Drewnowski A, Fulgoni V. Comparing the nutrient rich foods index with "go,"“slow," and “whoa” foods. J Am Diet Assoc. 2011;111(2):280-84. Link

24. World Health Organization. Physical activity Fact Sheets. Secondary Physical activity Fact Sheets 2015. Available at: http: / / www. who.int/mediacentre/factsheets/fs385/ en/ Link

25. Sleddens EF, Kremers SP, Thijs C. The Children's Eating Behaviour Questionnaire: factorial validity and association with Body Mass Index in Dutch children aged 6-7. Int J Behav Nutr Phys Act. 2008;5(1):49. Link

26. Jansen PW, Roza SJ, Jaddoe V, Mackenbach JD, Raat H, Hofman A, et al. Children's eating behavior, feeding practices of parents and weight problems in early childhood: results from the population-based Generation $\mathrm{R}$ Study. Int J Behav Nutr Phys Act. 2012;9(1):130-30. Link

27. McMinn AM, Van Sluijs EM, Wedderkopp N, Froberg K, Griffin SJ. Sociocultural correlates of physical activity in children and adolescents: findings from the Danish arm of the European Youth Heart study. Pediatr Exerc Sci. 2008;20(3):319-32. Link

28. Bassett-Gunter R, Leatherdale S. Mother knows best? Children's physical activity levels and preferences. The Health 
\& Fitness Journal of Canada. 2013;6(4):86-98.

29. Birch LL. Development of food preferences. Annu Rev Nutr. 1999;19(1):41-62. Link

30. Brunton G, Harden A, Rees R, Kavanagh J, Oliver S, Oakley A. Children and physical activity: a systematic review of barriers and facilitators: EPPI-Centre, Institute of Education, University of London, 2003.Link 